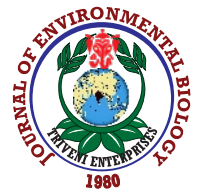

\title{
Monitoring of current land use pattern of Ramsar designated Kolleru Wetland, India using geospatial technologies
}

\author{
A. Shivakrishna', K.K. Ramteke', S. Kesavan', P. Prasad', B.C. Naidu', M. Dhanya ${ }^{1}$ and Z.J. Abidi"* \\ 'Department of ICAR-Central Institute of Fisheries Education, Fisheries Resource Management, Mumbai-400061, India \\ ${ }^{2}$ Department of CSIR-National Institute of Oceanography, Geological Oceanography, Goa-403 004, India \\ *Corresponding Author Email : zjabidi@cife.edu.in
}

\section{Abstract}

Aim: The present study is an attempt to analyze the land use pattern of Kolleru Lake in and around by using the techniques of remote sensing and GIS to detect the temporal changes of the Kolleru Lake.

Methodology: The 1938 and 1967 years topographic sheets and Landsat-5 TM of 1997 and Resoucesat-2 LISS 4 of 2017 satellite images were used and analyzed by the latest version of Arc GIS 10.4 and ERDAS IMAGINE 2016 (Version 16.00). Unsupervised and supervised classification was done for 1997 and 2017 images, respectively.

Results: It was estimated from the topographic map of 1938 that the total lake boundary area was $230.15 \mathrm{~km}^{2}$. Digital image processing of 2017 satellite data revealed that the lake area of $76.9 \mathrm{~km}^{2}$ $(32.45 \%)$ only remained degraded, extensively colonized by macrophytes. The land use/land cover maps of 1997 and 2017 revealed that lake area was significantly occupied by aquaculture which amounted to $84 \mathrm{~km}^{2}(36.53 \%)$ and $56 \mathrm{~km}^{2}(24.35 \%)$, respectively, and no aquaculture activity was reported from 1938 and 1967 toposheets.

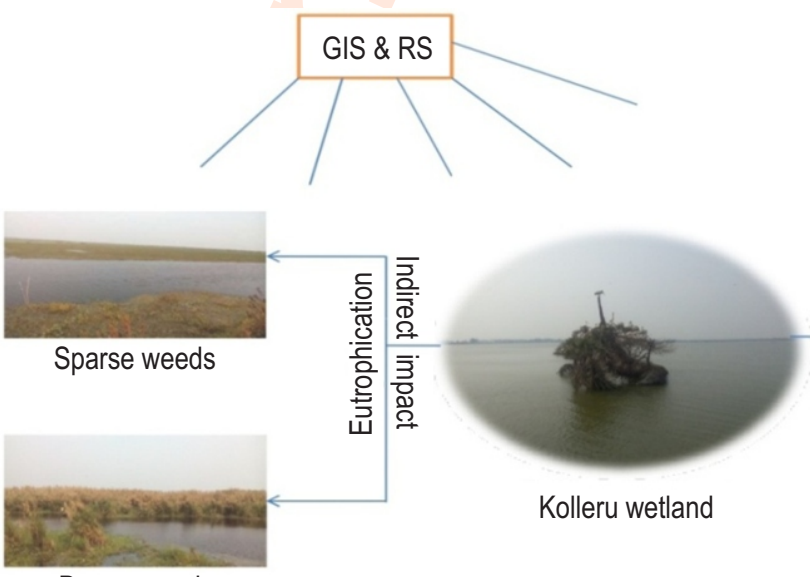

Dense weeds

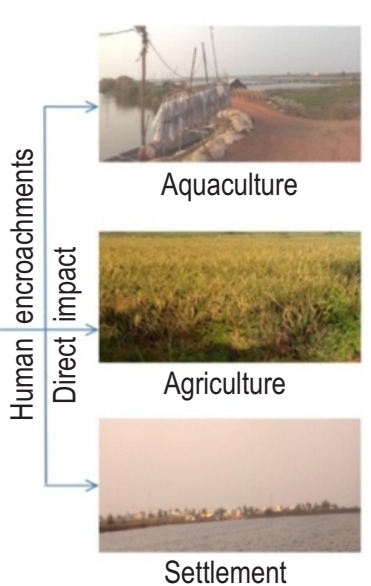

Settlement

Interpretation: The geospatial analysis

data gives accurate and reliable information and associated factors. The spatio-temporal analysis data provide a significant foundation for monitoring activities in other lake systems, and are applicable to monitoring wetland use patterns in other sites of international importance.

Key words: Eutrophication, Geospatial technology, Kolleru wetland, Macrophytes, Remote sensing

How to cite : Shivakrishna, A., K.K. Ramteke, S. Kesavan, P. Prasad, B.C. Naidu, M. Dhanya and Z.J. Abidi: Monitoring of current land use pattern of Ramsar Designated Kolleru Wetland, India using geospatial technologies. J. Environ. Biol., 42, 106-111 (2021). 


\section{Introduction}

Wetlands are the world's water filters, which provide many ecosystems and societal services, such as, water-quality improvement, flood mitigation, food security, habitat biodiversity and landscape aesthetics, however, they are under stress (Msusa, 2011; Kolka et al., 2016). Wetlands are ecologically sensitive and adaptive systems and are the most productive ecosystems on the earth (Ghermandi et al., 2011). Wetlands are still among the most vulnerable ecosystems, as they are often interfered by human activity, such as forestry, aquaculture, livestock farming, deforestation, use and urbanization of biological resources, vulnerability to invasive and climate change (Bassi et al., 2014; Song and Liu, 2016). Change in land use causes an unprecedented change in habitats and environmental processes that has a direct and indirect effect on biotic and abiotic components, which lead to transformation from local, regional and national to global scale (Agarwal et al., 2002; Chopra et al., 2001). Among the changes, the trend of human induced land use is regarded as one of the most significant factors for global changes in the environment (Chowdhury et al., 2009). The present rate of change is higher than the past, which has become a major human concern due to rising population resulting in climate change, loss of biodiversity, and water, soil and air pollution (Davis et al., 1994; Erle, 2013). The last few decades have seen an emerging trend in wetland destruction causing a decrease in landscape diversity and increase in fragmentation rates, eventually altering to ecological function of wetlands (Constanza et al., 1998; Chen and Lu, 2003; Bhattacharyya et al., 2013). The change in wetlands has affected the aquatic ecosystems hydrology through changes in precipitation and temperature, thus affecting human and other living organisms.

Further major shifts in land cover have been observed in the last few decades on spatial and temporal scale due to economic development and population growth (Mitsch and Gosselink, 1993; Davidson et al., 2018). Subsequently, the trend in wetland loss in India is similar to that in other developing countries, due to urbanization, land use changes, runoff from agriculture, growth of infrastructure and industrial pollution and variability in climate change (Nitin et al., 2014). Consequently, wetland conservation advocates for the study of wetland landscape, structure and functions, which is essential for understanding the causes and consequences of degradation, and for providing protection and preservation alternatives. Current monitoring and assessment of wetlands is an important practice to preserve the wetland and its environment, and geospatial techniques provide powerful wetland protection, planning and management tools (Nath et al., 2000). Remote sensors on satellites aid in sustainable fisheries management efforts. Keeping in view the above, the present study was undertaken to track the trend in land use trends and their effects on the wetland environment.

\section{Materials and Methods}

Study area: Lake Kolleru is the biggest Indian freshwater lakes located $20 \mathrm{~km}$ from the city of Eluru in Andhra Pradesh. Kolleru located between the deltas of Krishna and Godavari covers approximately $245 \mathrm{~km}^{2}$ area and serves as a natural flood- balancing reservoir for these two rivers. The lake is directly fed by water from the seasonal Budameru and Tammileru rivers, and the Krishna and Godavari systems connect it to over 68 in-flowing drains and channels. Lake Kolleru is connected to the Bay of Bengal by the Upputeru River at a distance of $60 \mathrm{~km}$. The lake area is covered in the Survey of India (SOI) toposheets $65 \mathrm{H} / 2$, $65 \mathrm{H} / 5$ and $65 \mathrm{H} / 6$. Lake Kolleru is a depression with a depth of 1 to $1.5 \mathrm{~m}$ with a maximum depth of $3 \mathrm{~m}$ during the south-west monsoon. The population within the lake area is close to two lakh. The main occupation of the people within the lake area is fishing, agriculture and cultivation.

Input data: In this study, different types of satellite images and topographic sheets were used. Topographic maps such as NE 44-15 (Published by Army Map Services in 1938) 65H/2, 65H/5 and $65 \mathrm{H} / 6$ (Published by Survey of India In 1967) were used. Satellite images of Landsat-5 TM and Resourcesat-2 LISS4 were used. Handheld Garmin GPS was used to collect GCP's (Ground Control Points) for ground truth verification. Complete ground truth verification was carried out using GS5+GPS with ARC PAD. The extent and latitude and longitude of different land and water use classes were verified. The boundary of aquaculture farm and agriculture field in the land use map was also checked and corrected through GPS readings, wherever necessary. For this study, the latest version of ArcGIS 10.4 software by ESRI and ERDAS IMAGINE 2016 version of the software were used.

GIS analysis: Topographic map of 1938-NE 44-15 was georeferenced, and lake boundary was extracted by using tools in ArcGIS 10.4. Topographic maps of $1967-65 \mathrm{H} / 2,65 \mathrm{H} / 3,65 \mathrm{H} / 6$ were geo-referenced and mosaicked using ArcGIS 10.4 and lake boundary was obtained by overlaying the 1938 toposheets lake boundary from mosaicked toposheets. All the topographic maps were projected under WGS1984 UTM Zone $44 \mathrm{~N}$. The land use of Kolleru in 1938 and 1967 was developed based on the classes given in the SOI topographic maps.

Digital image processing: Digital image processing of Landsat5 TM and Resourcesat-2 LISS4 images were done by using ERDAS imagine 2016. Due to the continuity of aquaculture farms and rice fields from adjacent areas to the lake, it was not possible to track the lake border from the image. Lake border derived from mosaic topographic maps was, therefore, considered to reflect the accurate original area of the lake.

The boundary of the lake, derived from the topographic map of 1938 , was overlaid with satellite images to extract the lake area. The rectified and registered image was subjected to different image enhancement techniques such as PCA (principal component analysis), ALR (automatic log residuals), NDWI (normalized difference water index), contrast stretching (increase the brightness of the original image) for clear visualization of the condition of the lake, and image rectification was done so that the spatial coordinates correspond to its geographic coordinates. Based on the image characteristic keys produced by the Space Application Center (SAC), the land-use classes from satellite images were established. Satellite images were classified into six classes and images were assessed for accuracy test to check the accuracy of classified images. 
Change detection analysis: To identify differences in the phenomenon by observing at different times, the classified land use map of 2017 was overlaid on the 1997 classified map. After integrating both maps, regrouping of added layers was carried out. Temporal changes under major land-use and land cover types were derived by the spatial intersection of 2017 and 1997 maps.

\section{Results and Discussion}

GIS analysis using a topographic map of 1938 revealed that the area of Kolleru lake was $230.15 \mathrm{~km}^{2}$ in 1938 . This extracted lake boundary map was used as a base/reference map. For further research, the lake boundary derived from a topography chart from 1938 was overlaid with geo-referenced toposheets and satellite images. The 1967 year topographic sheets were classified by overlaying the 1938 lake area boundary and lake area was classified into 4 classes. According to the 1967 year topographic sheets, lake area (which was extracted by overlaying the 1938 toposheet lake boundary) classification, in which the area covered by water body was $68.09 \mathrm{~km}^{2}(29.59 \%)$, the area liable to flood during rainy season was $77.36 \mathrm{~km}^{2}(33.61 \%)$ and the area under agriculture field was $84.64 \mathrm{~km}^{2}(36.77 \%)$.

The area occupied by human settlement was $0.06 \mathrm{~km}^{2}$ (0.02\%). By 1967, aquaculture was not developed since the topographical maps had no fish ponds. According to the 1938 and 1967 topographic sheets, lake water body was drastically reduced from $194.95 \mathrm{~km}^{2}(84.70 \%)$ in 1938 to $68.09 \mathrm{~km}^{2}(29.58 \%)$ in 1967, while the flood area increased from $34.04 \mathrm{~km}^{2}(14.79 \%)$ to $77.36 \mathrm{~km}^{2}(33.77 \%)$ between 1938 and 1967 . There was a drastic rise in agriculture from $1.1488 \mathrm{~km}^{2}(0.499 \%)$ to $84.636 \mathrm{~km}^{2}$ (36.77\%) between 1938 and 1967 due to more demand for agriculture in 1940s. In 1967, $0.064 \mathrm{~km}^{2}(0.027 \%)$ was occupied by human settlement, which was not recorded in 1938 toposheet.
The scenario started changing with the rise in aquaculture around the lake. The Landsat-5 TM remotely sensed subset image underwent unsupervised classification and classified into six classes. The resulting polygon distribution map prepared from 1997 satellite data showed that the region under aquaculture was $84.08 \mathrm{~km}^{2}(36.53 \%)$ and the lake water spread area was 28.42 $\mathrm{km}^{2}(12.35 \%)$, respectively. The area covered with sparse weeds occupied $45.62 \mathrm{~km}^{2}(19.82 \%)$ and dense weeds with 29.4741 $\mathrm{km}^{2}(12.80 \%)$. Agriculture in 1997 occupied $41.7933 \mathrm{~km}^{2}$ $(18.15 \%)$ of the lake area. The area of human settlement was about $0.72 \mathrm{~km}^{2}(12.34 \%)$. According to the Unsupervised classification of 1997 Landsat image, there was a significant change in the lake area from 1967 to 1997, out of the lake water body area of $68.09 \mathrm{~km}^{2}(29.58 \%)$ in the previous year, only $28.42 \mathrm{~km}^{2}(12.34 \%)$ remained as such, in the latter year.

The whole region was infested with aquatic weeds covering $77.30 \mathrm{~km}^{2}(33.61 \%)$ area of the lake reported by the 1967 flood-prone area. The present study revealed beginning of tremendous growth of aquatic weeds covering most area of the lake. The area covered by dense weeds was $29.47 \mathrm{~km}^{2}(12.80 \%)$, while sparse weeds occupied $45.62 \mathrm{~km}^{2}(19.82 \%)$; as compared to dense weeds growth of sparse weeds was more. The remaining area of $84.08 \mathrm{~km}^{2}(36.53 \%)$ was converted to aquaculture due to the enormous demand for aquaculture, agriculture area decreased from $84.63 \mathrm{~km}^{2}(36.77 \%)$ to $41.79 \mathrm{~km}^{2}$ $(18.15 \%)$ between 1967 to 1997 with increase in human settlement from $0.0640 \mathrm{~km}^{2}(0.027 \%)$ to $0.7281 \mathrm{~km}^{2}(0.33 \%)$. Fig. 1 (A) shows the land use/land cover map of the year 1997. The recent Resourcesat-2 subset image underwent supervised classification and classified into six classes. The lake classification from the 2017 satellite data revealed $56.04 \mathrm{~km}^{2}$ (24.35\%) area under aquaculture and the lake water spread area was $76.99 \mathrm{~km}^{2}(32.45 \%)$. The area occupied with sparse weeds was $52.18 \mathrm{~km}^{2}$ (22.67\%) and dense weeds $27.59 \mathrm{~km}^{2}$ (11.99\%).
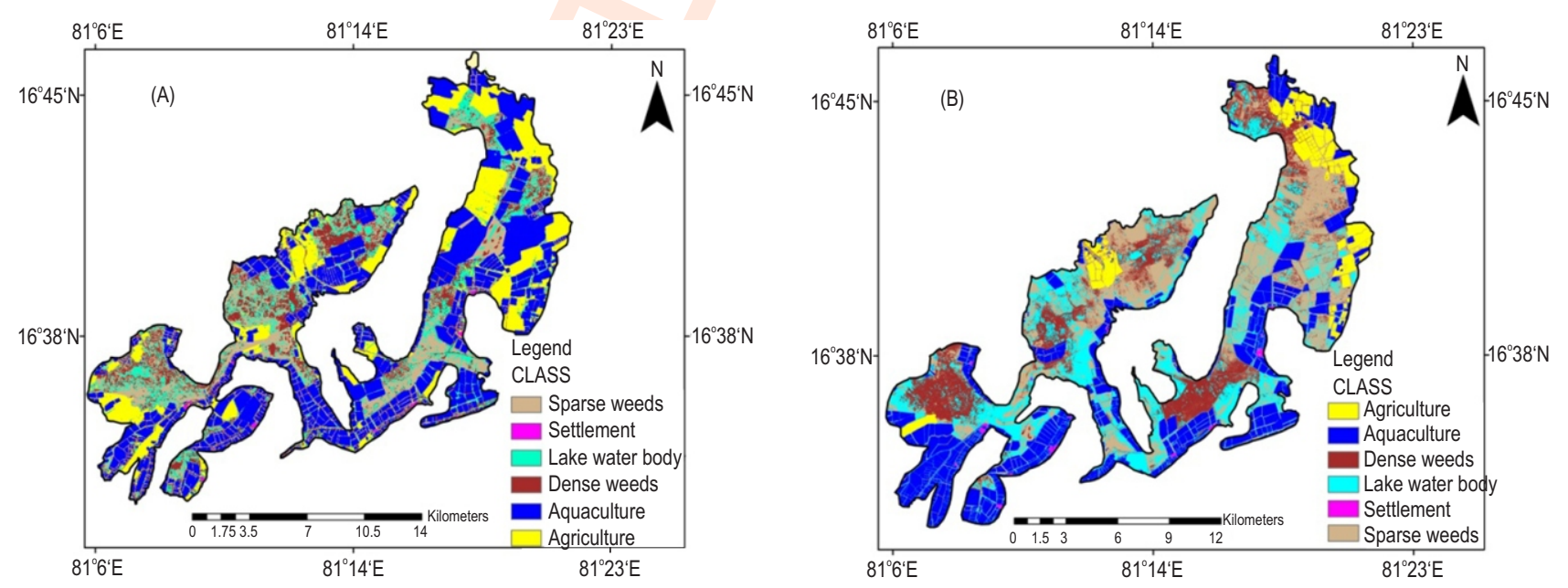

Fig. 1: Land use/land cover map of Kolleru lake in1997 (A) and 2017 (B), generated from on-screen classification of enhanced satellite images. 
Table 1: Land use/land cover status of Kolleru lake area in the year 1938, 1967, 1997 and 2017 (in km²), calculated from the classified topographic sheets and enhanced satellite images

\begin{tabular}{|c|c|c|c|c|c|c|c|c|}
\hline \multirow[b]{2}{*}{ Class name } & \multicolumn{4}{|c|}{ Area in $\mathrm{km}^{2}$} & \multicolumn{4}{|c|}{ Area in percentage } \\
\hline & 1938 & 1967 & 1997 & 2017 & 1938 & 1967 & 1997 & 2017 \\
\hline Lake body & 194.95 & 68.09 & 28.4229 & 76.9924 & 84.70 & 29.58 & 12.34 & 32.45 \\
\hline Agriculture & 1.1488 & 84.63 & 41.7933 & 15.8216 & 0.49 & 36.77 & 18.15 & 6.87 \\
\hline Aquaculture & - & - & 84.0816 & 56.0484 & - & - & 36.53 & 24.35 \\
\hline Dense weeds & - & - & 29.4741 & 27.5988 & - & - & 12.80 & 11.99 \\
\hline Sparse weeds & - & - & 45.6214 & 52.1813 & - & - & 19.82 & 22.67 \\
\hline Settlement & - & 0.0640 & 0.7281 & 1.5128 & - & 0.027 & 0.33 & 0.65 \\
\hline Liable to flood/Mud & 34.047 & 77.36 & - & - & 14.79 & 33.61 & - & - \\
\hline Total & 230.15 & 230.15 & 230.15 & 230.15 & 100 & 100 & 100 & 100 \\
\hline
\end{tabular}

Table 2: The area of lake Kolleru changed (in km²) from class to class during 1997 to 2017 , measured by using change detection analysis technique in Arc GIS

\begin{tabular}{llllllll}
\hline $\mathbf{2 0 1 7}$ & \multicolumn{7}{l}{} \\
\cline { 2 - 6 } Class & Aquaculture & Agriculture & Settlements & Sparse weeds & Dense weeds & Lake body & Total \\
\hline Aquaculture & 27.2412 & 4.9311 & 0.3471 & 17.6545 & 4.9699 & 27.7281 & 82.8719 \\
Agriculture & 9.6570 & 8.1143 & 0.1474 & 11.3506 & 1.9821 & 11.1371 & 42.4227 \\
Settlements & 0.1681 & 0.0052 & 0.2926 & 0.0241 & 0.0089 & 0.1041 & 0.6230 \\
Sparse weeds & 9.9590 & 0.9278 & 0.1676 & 8.4111 & 9.1934 & 16.8568 & 45.2957 \\
Donse weeds & 5.6209 & 0.4512 & 0.1545 & 6.8880 & 5.2904 & 11.3842 & 29.8892 \\
O. & 5.5313 & 0.8820 & 0.1385 & 5.7433 & 6.7433 & 9.8301 & 28.8985 \\
Lake body & 58.1775 & 15.3116 & 1.2477 & 50.0716 & 28.1880 & 77.0404 & 230.0368 \\
\hline
\end{tabular}

Rice fields occupied $15.82 \mathrm{~km}^{2}(6.88 \%)$ of the lake area. The area covered by human settlements amounted to $1.51 \mathrm{~km}^{2}(0.65 \%)$. The present study showed a huge change from 1997 to 2017 , out of the lake water area of $68.092 \mathrm{~km}^{2}$ in 1997, there was an increase in the area to $76.99 \mathrm{~km}^{2}$ in 2017 due to the operation Kolleru carried out during 2005 to 2006 . Aquaculture and agriculture occupied areas decreased from $84.08 \mathrm{~km}^{2}(36.53 \%)$ and $41.79 \mathrm{~km}^{2}(18.15 \%)$ to $56.04 \mathrm{~km}^{2}(24.35 \%)$ and $15.82 \mathrm{~km}^{2}$ $(6.87 \%)$, respectively, between 1997 to 2017 . While the area covered by dense weeds in 1997 was $29.47 \mathrm{~km}^{2}$ (12.80\%), and it slightly decreased to $27.59 \mathrm{~km}^{2}$ (11.99\%) from 1997 to 2017 and the area of sparse weeds slightly increased from $45.62 \mathrm{~km}^{2}$ $(19.82 \%)$ to $52.18 \mathrm{~km}^{2}(22.67 \%)$ from 1997 to 2017.

Table 1 shows temporal changes of Kolleru Lake from 1938 to 2017 and Table 2 shows the changes in land use patterns in Kolleru Lake between 1997 and 2017. Fig. 1(B) shows the land use/land cover map of the year 2017. Landsat-5 TM 1997 unsupervised classified image and Resourcesat-2 2017 supervised image was subjected to accuracy assessment test to check the level of accuracy and kappa statistics of each image. Each image was subjected to two accuracy assessment methods, such as random method and equalized random method. In the random method, supervised classifications showed $94.3 \%$ accuracy with 0.9210 kappa value and unsupervised classification showed $86.4 \%$ accuracy with 0.8723 kappa value. In the equalized random method, supervised classification showed $95.6 \%$ accuracy with 0.9320 kappa value and unsupervised classification showed $88.4 \%$ accuracy with 0.8912 kappa value, respectively. Lake area began to change in the 40's of the last century when the government started to parcel out the lake for agro production in order to increase the living standards in the lake area. For ages, native paddy variety was being grown at the bed of the Kolleru Lake and agriculture was carried out around the lake through irrigation system, with water being collected and transported from the lake to the croplands throughout the dry season (Narender, 1993).

Initially extensive crop cultivation methods were practiced, but gradually crop cultivation became more intensive (high yielding varieties replaced traditional varieties, usage of chemicals, and development of more and higher bunds to keep water out). In addition, the Government introduced cooperative farming in 1954 and set up 93 agricultural societies on 2.1 million acres. However, floods threatened the cultivated areas every year, as observed in the topographic maps. No aquaculture ponds were seen in during 1938 and 1967 topographic maps, although many areas of rice fields and settlements were present. In 1969, practically the entire lake was planted with large bands to keep the water out. By 1978, greater demand for fish from Calcutta resulted in enormous dike construction with the advancement of aquaculture and fish farming became more profitable by 
1984 (Narender, 1993). The topographic maps of 1990s shows increased area of aquaculture the reason behind this was farmers started converted their agriculture farms to aquaculture farms and the agriculture area reduced at that time. During the year 2001, a total of 1050 aquaculture ponds were noticed in the lake bed area and 38 dried fish ponds were also recorded (Amaraneni et al., 2004). Human settlements covered a small area $(0.65 \%)$ in 2017 , which was $0.33 \%$ only in 1997 . Human settlement near lake bed region had increased with rising aquaculture activities and main activity of people in lake area is fishing (Kumar et al., 2016). The statistics showed that aquaculture practices in the study area decreased from $56 \%$ to $24 \%$ during the year 1997 to 2017, respectively. The agrarian statistics markedly reduced from $36.77 \%$ in 1967 to $18.15 \%$ in 1997 and then declined from $18.15 \%$ to $6.87 \%$ in 2017 . The succession of Operation Kolleru increased the area of lake water body, sparse weeds and dense weeds by converting aquaculture and agriculture areas (Pattanaik et al., 2008 b).

Previous studies have shown that the lake area was 245 $\mathrm{km}^{2}$, according to 1930 topographic sheet (Rao et al., 2004). However, in the present study, it was observed there was a continuous decrease in the lake area from 1930 to 1967 toposheets like $230.15 \mathrm{~km}^{2}$ lake area in 1938 toposheet but certainly, there was a decrease in the area of $14.85 \mathrm{~km}^{2}$ from the year 1930 to 1938 . The lake area further decreased to $180.15 \mathrm{~km}^{2}$ in the 1967 topographic sheet, so there was a decrease in the lake area of $50 \mathrm{~km}^{2}$ from 1938 to 1967. In 2001, the Government of Andhra Pradesh decided to remove encroachments from the lake area to normalize the lake bed (Rao et al., 2006). In 2005-06, in compliance with the Supreme Court order, the Government of Andhra Pradesh conducted "Operation Kolleru". Even dynamites were used in the operation to blast the huge embankments and success of this operation resulted in the return of migratory birds to the lake (Pattanaik et al., 2008). Nevertheless, the ground reality does not seem to be as delightful as what one would expect after governmentaction (NageswaraRao et al.,2010; Rao et al., 2013).

According to Jayanthi et al. (2006), the overall lake loss between 1967 and 2004 was $109.02 \mathrm{~km}^{2}$ and aquaculture, occupying $99.74 \mathrm{~km}^{2}$ accounted for $55.3 \%$ of the lake area of 1967. Pattanaik et al. (2008) studied the aquaculture dynamics of Kolleru lake after Operation Kolleru and found that aquaculture ponds covering $158.5 \mathrm{~km}^{2}$ in 2000 and after the implementation of demolition reduced to $15 \mathrm{~km}^{2}$. NageswaraRao et al. (2010) noticed that the aquaculture ponds occupied $11.38 \mathrm{~km}^{2}$ only area in lake bed $56.04 \mathrm{~km}^{2}$ whereas in the present study, a notable increase in the aquaculture encroachment in the lake bed was observed. The ecosystem of the lake was significantly affected due to agriculture and aquaculture, increased industrial activity, growing numbers of human settlers and infrastructure building such as roads, etc .(Rao et al., 2000; Sellamuttu et al., 2012). Lake quality is deteriorating due to effluent inflow into the lake from surrounding industries (Amaraneni et al., 2004; Kumar et al., 2016). As the lake is shallow, nutrients reach higher levels in the lake and support numerous weeds, and floods are induced by siltation. Many seasonal migratory birds which are considered as endangered species hardly visit the place due to insufficient availability of fish, whose breeding capability declined due to eutrophication and abundant weed growth in lake (Venot et al., 2008). . Due to lack of regulation of seaward flow, monsoon season progressively increases high flood line, causing major flood problems in the surroundings. There is a need to widen and increase the depth of Upputeru River to increase its discharging capacity during flood times (Karanam et al., 2013). It is necessary to construct regulators on the Upputeru River which can obstruct seawater intrusion into the lake. There is a need to widen and increase the depth of Upputeru River to increase its discharging capacity during flood times.

Analysis of spatial data using satellite images revealed that the lake region was dramatically reduced and that its appearance was modified profoundly. In the last $70-80$ years, people have messed with the natural state of the lake in an unprecedented way. The initiatives usually centered on the manipulation and extension of one or two of the facilities that the lake could provide. Generally, this was only feasible at the cost of other ecosystem services. Integrated analysis of the present study has generated extensive and updated datasets and tangible evidence on the degradation of Kolleru ecosystem. The intersected map produced by change detection analysis based on topographic maps and satellite data from 1938 to 2017 revealed the loss of a potential fisheries site of the Kolleru Lake. In the last four decades, numerous natural and human activities have significantly depleted the lake area. Kolleru is the best example of the impact of anthropogenic activities on the lakes. Hence, its conservation as biodiversity reserve requires minimal use of wetland by humans. To integrate, all the above land and water resources parameters suggested appropriate scientific management strategies, and more stringent restoration measures conserve this fragile green inter-deltaic environment in the coastal region. The result would be useful for planning and sustainable aquatic resource management strategies relying upon it.

\section{Acknowledgments}

The authors are grateful to the Director ICAR-Central Institute of Fisheries Education Mumbai for providing Institutional fellowship to one of the researcher Mr. A. Shivakrishna. The authors wish to express their gratitude to HOD, FRHPHM Dr. B.B. Nayak for encouragement. Thanks are also due to Mr. Dande Kranthi Kumar Ph.D. scholar for his kind help during the study period.

\section{Add-on Information}

Authors' contribution: A. Shivakrishna: Data collection, processing, analysis and writing; K.K. Ramteke: Guidance in data interpretation and validation; S. Kesavan: Formal analysis of data and data curation; P. Prasad: Methodology and conceptualization; B.C. Naidu:Ground truth verification and 
formal analysis; M. Dhanya: Guidance in data pre and post processing;Z.J. Abidi: Validation and overall supervision.

Research content: The research contents is original and has not been published elsewhere

Ethical approval: NotApplicable.

Conflict of interest: The author declares that there is no conflict of interest.

Data from other sources: NotApplicable.

Consent to publish: All authors agree to publish the paper in Journal of Environmental Biology.

\section{References}

Agarwal, C., G.M. Green, J.M. Grove, T.P. Evans and C.M. Schweik: A review and assessment of land-use change models: Dynamics of space, time and human choice. Gen. Tech. Rep. NE-297. Newton Square, PA: US Department of Agriculture, Forest Service, Northeastern Research Station, 61, 297 (2002).

Amaraneni, S.R., S. Singh and P.K. Joshi: Mapping the spatial distribution of air and water pollutants in Kolleru Lake, India using geographical information systems (GIS). Manag. Eviron. Qual. Int. J., 15, 584-607 (2004).

Bassi, N., M.D. Kumar, A. Sharma and P. Pardha-Saradhi: Status of wetlands in India: A review of extent, ecosystem benefits, threats and management strategies. J. Hydrol. Regi. Stu., 2, 1-19 (2014).

Bhattacharyya, A., K.N. Rao, S. Misra, K.C.V. Nagakumar, G. Demudu and B.H. Malini: Palynological indicators of mangrove habitat in the Kolleru Lake region during the Early to Middle Holocene. Curr. Sci., 104, 121-125(2013).

Burrough, P.A.: Principles of Geographical: Information Systems for Land Resource Assessment. Grocar. Int., 1, 54 (1986).

Chen, Y. and X. Lu: The wetland function and research tendency of wetland science Wetland Sci., 1, 7-10 (2003).

Chopra, R., V.K. Verma and P.K. Sharma: Mapping, monitoring and conservation of Harike wetland ecosystem, Punjab, India, through remote sensing. Int. J. Remote Sensing, 22, 89-98 (2001).

Chowdhury, A., M.K. Jha, V.M. Chowdhary and B.C. Mal: Integrated remote sensing and GIS-based approach for assessing groundwater potential in West Medinipur district, West Bengal, India. Int. J. Remote Sensing, 30, 231-250 (2009).

Constanza, R., D. Ralph, G. Rudolfde, F. Stephen, G. Monica, H. Bruce, L. Karin, N. Shahid, V.O. Robert, P. Jose, G.R. Robert, S. Paul and B.M. van den: The value of ecosystem services: Putting the issues in perspective. Ecol. Econ., 25, 67-72 (1998).

Davidson, N.C., E.F. Chouinard and C.M. Finlayson: Global extent and distribution of wetlands trends and issues. Mari. Freshwater Res., 69, 620-627 (2018).

Davis, T.J.: The Ramsar Convention Manual: A guide to the convention on wetlands of international importance especially as waterfowl habitat. Gland (Switzerland) Ramsar Convention Bureau, p. 207 (1994).

Erle, C.E.: Sustaining biodiversity and people in the world's anthropogenic biomes. Curr. Opin. Environ. Sust., 5, 368-372 (2013).

Ghermandi, A., J.C.J.M. van den Bergh, L. Brander, H. de Groot and P. ALD Nunes: The economic value of wetland conservation and creation: A meta-analysis. Econometrics: Appl. Economet. Model. eJ., (2008). DOl:10.2139/ssrn.1273002

Jayanthi, M., P.N. Rekha, N. Kavitha and P. Ravichandran: Assessment of impact of aquaculture on Kolleru Lake (India) using remote sensing and geographical information System. Aqua. Res., 37, 1617-1626 (2006).

Karanam, H., A.R. Nadipena, V.R. Velaga, J. Gummapu and A. Edara: Land use/land cover patterns in and around Kolleru lake, Andhra Pradesh, India using remote sensing and GIS techniques. Int. J. Rem. Sen. Geosci., 2, 2 (2013).

Kareddula, S.: Monitoring and quantifying the environmental change detection of Lake Kolleru and the surrounding mandals using remote sensing techniques. Southern Illinois University, Carbondale, pp. 202 (2011)

Kolka, R.K., D. Murdiyarso, J.B. Kauffman and R.A. Birdsey: Tropical wetlands, climate, and land-use change: Adaptation and mitigation opportunities. Wetlands Ecol. Manage., 24, 107-112 (2016).

Kumar, K., C.V. Naga, G. Demudu, B.H. Malini, K.N. Rao and S. Kubo: Geospatial analysis of the changing environment of Kolleru Lake, the largest freshwater wetland in India. Wetlands, 36, 745-758 (2016).

Mitsch, W. and J. Gosselink: Wetlands. $2^{\text {nd }}$ Edn., Wiley, New York, p. 722 (1993).

Msusa, $H .:$ Sustainable utilization of wetlands for food security: A case study of the Simulemba traditional Authority in the Kasungu District of Malawi. J. Develop. Sustain. Agricul., 6, 86-100 (2011).

Nageswara Rao, K., K.N. Kumar, P. Subraelu, G. Demudu, B.V. Reddy and B.H. Malini: Kolleru lake revisited: The post 'Operation Kolleru' scenario. Curr. Sci., 98, 1289-1291 (2010).

Narender, K.: The broken mirror. Down to Earth, 2, 3-4 (1993).

Nath, S.S., J.P. Bolte, L.G. Ross and J.A. Manjarrez: Applications of geographical information systems (GIS) for spatial decision support in aquaculture. Aquacul. Engine., 23, 233-278 (2000).

Nitin, B., M.D. Kumar, S. Anuradha and P. Pardha-Saradhi: Status of wetlands in India: A review of extent, ecosystem benefits, threats and management strategies. J. Hydrol. Reg. Stud., 2, 1-19 (2014).

Pattanaik, C., S.N. Prasad, N. Nagabhatla and C.M. Finlayson: Kolleru regains its grandeur. Curr. Sci., 94, 9-10 (2008).

Pattanaik, C., N. Nagabhatla, S.S. Sellamuttu, S.N. Prasad and C.M. Finlayson: Remote sensing application to study the aquaculture dynamics in Kolleru Lake, India. In: Proceedings of the $29^{\text {th }}$ Asian Conference on Remote Sensing (ACRS), Colombo, Sri Lanka, pp. 10-14 (2008)

Rao, M.V., I.V. Ramana, S.K. Sasamal, S.B. Choudhury and S.K. Bhan: Change detection studies in and around Kolleru lake using high resolution data (2000).

Rao, S.A., S. Singh and P.K. Joshi: Mapping the spatial distribution of air and water pollutants in Kolleru Lake, India using geographical information systems (GIS). Manag. Environ. Qual. Int. J.,15, 584607 (2004)

Rao, K.N., G.M. Krishna and B.H. Malini: Kolleru lake is vanishing-A revelation through digital processing of IRS-1D LISS-III sensor data. Curr. Sci., 86, 1312-1316 (2004).

Rao, J.R., J. Jairath and P. Umesh: Pollution through aqua culture, Kolleru Wildlife Sanctuary. Econo. Politi. Weekly, 41, 585-587 (2006).

Rao, J.C.S., G.S. Chalam and C.S. Raju: Ornamental fish diversity of Lake Kolleru, the only Ramsar site in Andhra Pradesh, India. Bull. Enviro. Pharmacol. Life Sci., 2, 48-55 (2013)

Sellamuttu, S.S., S. de Silva, N. Nagabhatla, C. Max Finlayson, C. Pattanaik and N. Prasad: The ramsar convention's wise use concept in theory and practice: An inter-disciplinary investigation of practice in Kolleru Lake, India. J. Int. Wildlife Law Policy, 15, 228250 (2012)

Song, H. and X. Liu: Anthropogenic effects on fluxes of ecosystem respiration and methane in the Yellow River Estuary, China. Wetlands, 36, 113-123 (2016).

Venot, Jean-Philippe, B. R. Sharma, and K. V. G. K. Rao: Krishna basin development: Interventions to limit downstream environmental degradation. J. Environ. Develop., 17, 269-291 (2008). 